This is the author's final, peer-reviewed manuscript as accepted for publication. The publisher-formatted version may be available through the publisher's web site or your institution's library.

\title{
Ultrasonic vibration-assisted pelleting of wheat straw: a predictive model for energy consumption using response surface methodology
}

Xiaoxu Song, Meng Zhang, Z. J. Pei, Donghai Wang

\section{How to cite this manuscript}

If you make reference to this version of the manuscript, use the following information:

Song, X., Zhang, M., Pei, Z. J., \& Wang, D. (2014). Ultrasonic vibration-assisted pelleting of wheat straw: A predictive model for energy consumption using response surface methodology. Retrieved from http://krex.ksu.edu

\section{Published Version Information}

Citation: Song, X., Zhang, M., Pei, Z. J., \& Wang, D. (2014). Ultrasonic vibrationassisted pelleting of wheat straw: A predictive model for energy consumption using response surface methodology. Ultrasonics, 54(1), 305-311.

Copyright: @ 2013 Elsevier B.V.

Digital Object Identifier (DOI): doi:10.1016/j.ultras.2013.06.013

Publisher's Link:

http://www.sciencedirect.com/science/article/pii/S0041624X13001856

This item was retrieved from the K-State Research Exchange (K-REx), the institutional repository of Kansas State University. K-REx is available at http://krex.ksu.edu 


\title{
Ultrasonic Vibration-assisted Pelleting of Wheat Straw: A Predictive Model for Energy \\ Consumption Using Response Surface Methodology
}

\author{
Xiaoxu Song \\ Department of Industrial and Manufacturing Systems Engineering \\ Kansas State University \\ Manhattan, KS 66506, USA \\ Meng Zhang \\ Department of Industrial and Manufacturing Systems Engineering \\ Kansas State University \\ Manhattan, KS 66506, USA \\ Z.J. Pei (corresponding author) \\ Professor \\ Department of Industrial and Manufacturing Systems Engineering \\ Kansas State University \\ Manhattan, KS 66506, USA \\ Email: zpei@ksu.edu \\ Telephone: (01)785-532-3436 \\ Fax: 785-532-3738 \\ Donghai Wang \\ Professor \\ Department of Biological and Agricultural Engineering \\ Manhattan, KS 66506, USA \\ Email: dwang@ksu.edu
}




\begin{abstract}
Cellulosic biomass can be used as a feedstock for biofuel manufacturing. Pelleting of cellulosic biomass can increase its bulk density and thus improve its storability and reduce the feedstock transportation costs. Ultrasonic vibration-assisted (UV-A) pelleting can produce biomass pellets whose density is comparable to that processed by traditional pelleting methods (e.g. extruding, briquetting, and rolling). This study applied response surface methodology to the development of a predictive model for the energy consumption in UV-A pelleting of wheat straw. Effects of pelleting pressure, ultrasonic power, sieve size, and pellet weight were investigated. This study also optimized the process parameters to minimize the energy consumption in UV-A pelleting using response surface methodology. Optimal conditions to minimize the energy consumption were the following: ultrasonic power at 20\%, sieve size at $4 \mathrm{~mm}$, and pellet weight at $1 \mathrm{~g}$, and the minimum energy consumption was $2.54 \mathrm{Wh}$.
\end{abstract}

KEYWORDS: cellulosic biomass, energy consumption, response surface methodology, ultrasonic vibrationassisted (UV-A) pelleting

\title{
1. INTRODUCTION
}

Liquid transportation fuels currently used in the United States are mainly petroleum-based [1-3]. In 2011, the U.S. transportation sector consumed about 18.95 million barrels of petroleum per day and half of it was imported [4,5]. The dependence on foreign petroleum threatens the nation's energy security. Another issue of consuming petroleum-based transportation fuels is greenhouse gas (GHG) emissions. One-third of the total carbon dioxide emissions in the U.S. are from the use of petroleum-based transportation fuels [6-8].

Biofuels, particularly cellulosic biofuels, can help addressing these issues. Biofuels have the potential to reduce GHG emissions by as much as $86 \%$ compared to gasoline [9]. Because biofuels are made from renewable, plantbased feedstocks, the carbon dioxide released during fuel combustion is 'recycled' by the plant as it grows [10]. Cellulosic biofuels are produced from cellulosic biomass, including agricultural and forestry residues and dedicated energy crops. Unlike other type of feedstocks (e.g. corn, sugar cane, and soybean) for biofuels, cellulosic biomass does not compete with food production for the limited agriculture land [11,12]. 
However, cellulosic biomass feedstocks have low bulk density, resulting in high costs in their transportation and storage. Densification of cellulosic biomass into pellets [13] can increase the bulk density from 40 to $250 \mathrm{~kg} / \mathrm{m}^{3}$ for cellulosic biomass materials to as high as $1200 \mathrm{~kg} / \mathrm{m}^{3}$ [14].

Traditional pelleting methods (e.g. extruding, briquetting, and rolling) [15] generally involve high pressure, high-temperature steam or usage of binder materials. Ultrasonic vibration-assisted (UV-A) pelleting is a new pelleting method developed by the authors [16,17]. UV-A pelleting, without using binder materials or hightemperature steam, can produce biomass pellets whose density is comparable to that processed by traditional pelleting methods [18] Moreover, cellulosic biomass (wheat straw, corn stover, switchgrass, and sorghum stalk) processed with UV-A pelleting had more than 30\% higher sugar yield (proportional to the biofuel yield) than biomass pellets processed without UV-A pelleting [17].

The literature on UV-A pelleting includes experimental investigations on pellet quality, sugar yield, pelleting temperature, charring, and energy consumption [18-25]. Energy consumption in UV-A pelleting not only contributes to the costs of cellulosic biofuel manufacturing, but also affects the energy balance and the life cycle of cellulosic biofuel manufacturing.

This paper, for the first time, developed a predictive model on the energy consumption in UV-A pelleting. The experimental data obtained were used for the optimization of the process parameters by means of response surface methodology (RSM) with a Box-Behnken experimental design. RSM is an effective statistical technique for optimizing multifactor experiments, building models, evaluating the effects of several parameters for desirable responses. The eventual objective of RSM is to determine the optimum operating parameters for the system, or to determine the region that satisfies the operating specifications [26]. RSM has been reported to optimize the process parameters in biofuel production [27], but this was the first effort that RSM was applied to optimizing the process parameters in order to minimize the energy consumption in UV-A pelleting.

\section{EXPERIMENTAL PROCEDURE AND CONDITIONS}

\subsection{Cellulosic biomass preparation}

The cellulosic biomass used in this investigation was wheat straw. The wheat straw was harvested by the Deines Farm in Northwest Kansas. The wheat straw had been run through a John Deere combine (Model 9600, 
Deere \& Company, Moline, IL, USA). The combine removed grains from straw and chaff. Wheat straw and chaff exited through the back of the combine, and had an average length of $250 \mathrm{~mm}$. After being collected, wheat straw was stored indoors until this study.

Wheat straw was processed by a knife mill (Model SM 2000, Retsch, Inc., Haan, Germany). Figure 1 shows the milling chamber of the knife mill. The knife mill used a $240-\mathrm{V}, 2.2-\mathrm{kW}$ electric motor with a fixed rotation speed (1,720 round/minute). Three cutting blades (95 mm long and $35 \mathrm{~mm}$ wide) were mounted on the rotor. Four shear bars were mounted on the inside wall of the milling chamber. There was a 3-mm gap between a cutting blade and a shear bar. Wheat straw was cut between the cutting blades and the shear bars. There sieves with different sieve sizes $(2,4$, and $8 \mathrm{~mm})$ were used to control wheat straw particle size. It is noted that these three sieves were used to produce wheat straw particles with three size levels. Sieve size $(2,4$, or $8 \mathrm{~mm})$ only represented the three size levels, but not the actual size in any dimension (length, width, or thickness) of a particle. Wheat straw particles would fall through the openings on the sieve installed until they were cut small enough. Wheat straw particles after milling were kept in Ziploc ${ }^{\circledR}$ bags until being used for further experiments.

Biomass moisture content $(M C)$ was measured by following the National Renewable Energy Laboratory procedure (NREL/TP-510-42621) [28]. About $2.5 \mathrm{~g}$ of biomass was placed in an aluminum weighing dish and dried in an oven at $105^{\circ} \mathrm{C}$ for $24 \mathrm{~h}$. The loss in weight of the biomass after oven drying was recorded. Moisture content was calculated as follows:

$$
\text { Moisture content }(M C)(\%)=\frac{\text { Loss in weight }}{\text { Weight of biomass before drying }} \times 100 \%
$$

The moisture content of the wheat straw particles in this study was 7\%. After knowing the moisture content, biomass dry weight could be calculated as follows:

$$
\text { Dry weight }(g)=(1-M C) \times \text { weight of biomass with moisture }
$$

Biomass weight reported in this study is dry weight.

\subsection{Experimental setup and procedure}

Figure 2 shows a schematic illustration of the experimental set-up for UV-A pelleting. UV-A pelleting experiments were performed on a modified ultrasonic machine (Model AP-1000, Sonic-Mill, Albuquerque, NM, 
USA). The machine included a power supply (which converts $60 \mathrm{~Hz}$ electrical power into 20,000 $\mathrm{Hz}$ electrical power), a converter (which converts high frequency electrical energy into mechanical vibration), and a titanium tool. The tip of the tool was a solid cylinder with a flat end (17.4 $\mathrm{mm}$ in diameter).

Before one pelleting test, the weight of the wheat straw particles was measured by an electronic scale. This weight was referred to as the pellet weight. Then wheat straw particles were loaded into an aluminum mold. The mold was consisted of three parts. The upper two parts formed a cylindrical cavity (18.6 mm in inner diameter) and the bottom part was a square disk, serving as a base. They were assembled together with pins.

The pneumatic cylinder was driven by the compressed air provided by a $1.2 \mathrm{~kW}, 12.5 \mathrm{~L}$. air compressor (Sears, Roebuck and Co., Hoffman Estates, IL, USA). The air pressure in the pneumatic cylinder was controlled by a pressure regulator. A higher air pressure in the cylinder led to a higher pressure applied on the biomass in the mold by the tool.

In each pelleting test, the pelleting duration was $120 \mathrm{~s}$. After $120 \mathrm{~s}$, the tool was retracted and the mold was disassembled to unload the pellet. A finished UV-A pellet is shown in Figure 3.

\subsection{Measurement of energy consumption}

Energy consumption in this study was referred to as the electrical energy consumed by the power supply in the UV-A pelleting set-up. A Fluke 189 multimeter and a Fluke 200 AC current clamp (Fluke Corp., Everett, WA, USA) were used to measure the electric current, as shown in Figure 2. The power line to the power supply has three wires: black, red, and green wires. The current clamp was clamped on the black wire to measure the current. The data was collected using the Fluke View Forms software (Fluke Corp., Everett, WA, USA). The sampling rate was two readings per second. After the tool touched the biomass in the mold, the power supply was switched on and the software started collecting the current data. After 120 s, the software stopped collecting data and power supply was switched off.

The software recorded the average current $\left(I_{A V E}\right)$. The voltage $(V)$ was $120 \mathrm{~V}$. The energy consumed during the $120 \mathrm{~s}$ of pelleting duration can be calculated using the following equation [29]:

$$
E=\frac{V \times I_{A V E} \times 120}{3600}(W h)
$$




\subsection{Design of experiments using Response Surface Methodology (RSM)}

According to the results of experimental investigations conducted previously [19], the appropriate parameters for obtaining a qualified pellet (means that produced pellet would stay in condensed cylindrical shape without cracks or getting loose) were selected. A Box-Behnken experimental design was employed to obtain the response surface model. Four process parameters: pelleting pressure, ultrasonic power, sieve size, and pellet weight were selected as independent variables in the model, because there were single factor experimental studies on the effects of the these four process parameters reported in the literature [30,31].Three coded levels of settings were used for the process parameters, as shown in Table 1 . In this study, a random order of 27 runs was generated by a design of experiment software (Version 16, Minitab, Inc., State College, PA, USA).

\section{RESPONSE SURFACE MODEL}

Results of energy consumption in UV-A pelleting are shown in Table 1. Through analysis in the Minitab software, a response surface model for the energy consumption was obtained. The model can be described by the following equation:

$$
\begin{aligned}
& E=4.474-0.0434 \times A-0.0332 \times B-0.2781 \times C-0.4470 \times D \\
& +0.0338 e^{-3} \times A^{2}+0.9983 e^{-3} \times B^{2}+0.0152 \times C^{2}+0.0278 \times D^{2} \\
& +0.0002 \times A \times B+0.0026 \times A \times C+0.001 \times A \times D \\
& -8.9655 e^{-5} \times B \times C+0.0106 \times B \times D+0.0307 \times C \times D
\end{aligned}
$$

where E, A, B, C, and D represent energy consumption, pelleting pressure, ultrasonic power, sieve size, and pellet weight, respectively. Analysis of variance (ANOVA) was then performed to remove the insignificant terms (p-value > 0.05), resulting in the following model:

$$
\begin{aligned}
& E=3.0342-0.0184 \times B-0.1562 \times C-0.2957 \times D \\
& +0.8442 e^{-3} \times B^{2}+0.0132 \times C^{2}+0.0106 \times B \times D+0.03089 \times C \times D
\end{aligned}
$$

The ANOVA indicated that the model is highly statistically significant (p-value $<0.0001$ ). The coefficient of determination (the ratio of the explained variation to the total variation) $R^{2}$ equals to 0.97 . This suggests that the response surface model could provide good predictions. The lack-of-fit test [32,33] showed that the lack-of-fit was insignificant, indicating that the model fits well with the experimental data. 
The response surface model explicitly relates energy consumption in UV-A pelleting to process parameters. Energy consumption can be predicted from the response surface model as long as the process parameters varied within the tested experimental ranges in this study.

\section{PREDICTED EFFECTS OF PROCESS PARAMETERS}

The ANOVA showed that ultrasonic power, sieve size, and pellet weight had significant effects on the energy consumption in UV-A pelleting.

\subsection{Effects of ultrasonic power}

Effects of ultrasonic power on the energy consumption in UV-A pelleting, as predicted by Eq. (5), are shown in Figure 4A. Energy consumption increased as ultrasonic power increased from $20 \%$ to $40 \%$ for different levels of pellet weight. This trend could be explained as that since ultrasonic power was proportional to the vibration amplitude of the tool, as ultrasonic power increased, more energy would be consumed to generate higher vibration amplitude of the tool. The same trend was also observed on a rotary ultrasonic machine (Model Series 10, SonicMill, Albuquerque, NM, USA) containing the same power supply and made by the same manufacturer as the unit used in this work [34]. A different trend was reported by Zhang et al. [30], who studied effects of ultrasonic power on energy consumption in UV-A pelleting of wheat straw, sorghum stalk, big bluestem, and corn stover. They found that energy consumption decreased as ultrasonic power increased from $50 \%$ to $100 \%$. It is noted that in their work, pellet density was controlled as a constant. Once a pellet in the mold reached this constant density, the UV-A pelleting process ended. This procedure indicated that pellets were not produced with the same pelleting duration. Unlikely, in this present work, each pellet was produced with 120 s pelleting duration. This difference could be a factor in the inconsistent trends reported by these two works.

Ultrasonic power affected not only energy consumption but also other outputs, such as pellet quality (pellet density, pellet durability and spring-back), and sugar yield (proportional to ethanol yield). Pellet durability measures the ability of pellets to withstand impact and other forces during transportation and storage [35]. Spring-back measures the expansion of a pellet after taken out of the mold [35]. Zhang et al. [36] reported that, pellet quality was improved as ultrasonic power increased from $30 \%$ to $50 \%$ in UV-A pelleting of sorghum stalk. The same trend was also reported by Zhang et al. [25] in UV-A pelleting of wheat straw. 
Zhang et al. [36] studied effects of ultrasonic power in UV-A pelleting of sorghum stalk on sugar yield. Sugar yield increased as the ultrasonic power increased from 30\% to 55\%. Similar results were also observed by Zhang et al. [25] using wheat straw biomass.

\subsection{Effects of sieve size}

Effects of sieve size on the energy consumption as predicted by Eq. (5) are shown in Figure 4B. Energy consumption increased as sieve size increased at all the three levels of ultrasonic power. A possible explanation was that larger sieve size resulted in a lower bulk density of the particles in the mold initially than that of particles produced by smaller sieve size. Particles with lower bulk density might require more energy input from UV-A pelleting to be condensed into a pellet. In the literature, there are no reports about the effects of sieve size on the energy consumption in UV-A pelleting. However, Svihus et al. [37] studied effects of sieve size on energy consumption in pelleting of wheat using a pellet press (Münch-Edelstahl, Wuppertal, Germany) with 350,000 rpm and 5,000 kg/h capacity. The results showed that there were no significant differences in energy consumption when using different sieve sizes ( 3 or $6.1 \mathrm{~mm}$ ). This inconsistent observation might be caused by the distinct pelleting mechanism and the significant difference on machine capacity.

Sieve size affected not only the energy consumption but also other outputs, such as pellet quality (pellet density, pellet durability and spring-back) and sugar yield of the pellets produced by UV-A pelleting. Zhang et al. [25] studied pellet quality in UV-A pelleting of wheat straw particles made by knife milling using a $2^{4}$ full factorial design with two levels of sieve size $(1$ and $2 \mathrm{~mm})$. Wheat straw particles milled with $1 \mathrm{~mm}$ sieve size produced pellets with higher density, higher durability, and smaller spring-back. Zhang et al. [38] also studied effects of sieve size (with five levels: 0.25, 1, 2, 1.5 and $8 \mathrm{~mm}$ ) on pellet quality in UV-A pelleting of wheat straw. Results showed that wheat straw particles milled with the smallest sieve size $(0.25 \mathrm{~mm})$ had the best pellet quality.

Theerarattananoon et al. [39] studied effects of sieve size on pellet quality in ring-die pelleting of wheat straw, corn stover, big bluestem, and sorghum stalk. All the four types of biomass were processed by hammer milling with two levels of sieve size (3.2 and $6.5 \mathrm{~mm}$ ). Sieve size did not have significant effects on pellet density and durability. Tabil and Sokhansanj [40] also studied effects of sieve size on durability in ring-die pelleting of alfalfa. They found that the increase of sieve size from 3.2 to $6.5 \mathrm{~mm}$ resulted in no significant change in pellet durability. 
Effects of sieve size on sugar yield of cellulosic biomass were also reported. In UV-A pelleting, Zhang et al. [25] found that pellets made of wheat straw particles milled with $2 \mathrm{~mm}$ sieve produced 50\% higher sugar yield than those made of particles milled with $1 \mathrm{~mm}$ sieve. In ring-die pelleting, Theerarattananoon et al. [39] reported that the use of a larger sieve size $(6.5 \mathrm{~mm})$ resulted in pellets with higher sugar yield than smaller sieve size $(3.2 \mathrm{~mm})$ for wheat straw, corn stover, bluestem, and sorghum stalk.

\subsection{Effects of pellet weight}

Effects of pellet weight on the energy consumption in UV-A pelleting are shown in Figure 4C. Energy consumption increased linearly as pellet weight increased at different levels of sieve size. In the literature, there are no reports about the effects of pellet weight on energy consumption in UV-A pelleting. Tang et al. [41] studied effects of pellet weight on pellet density, durability, pelleting temperature, and sugar yield in UV-A pelleting. As pellet weight varied from $0.5,1,1.5,2,2.5$, to $3 \mathrm{~g}$, pellet density, durability, pelleting temperature, and sugar yield first increased and then decreased. The highest density, durability, pelleting temperature, and sugar yield were all obtained when pellet weight was at $1.5 \mathrm{~g}$ level.

\subsection{Interaction effects}

Two of the two-factor interaction effects (of ultrasonic power and pellet weight, and of sieve size and pellet weight) are shown in Figures 5 and 6, respectively. For interaction effects of ultrasonic power and pellet weight, the energy consumption increased from 3.49 to $3.99 \mathrm{Wh}$ (increased by $0.5 \mathrm{Wh}$ ) at a higher ultrasonic power level (40\%), and increased from 2.63 to $2.70 \mathrm{Wh}$ (increased by $0.07 \mathrm{Wh}$ ) at a lower ultrasonic power level (20\%), when pellet weight increased from 1 to $3 \mathrm{~g}$, as shown in Figure 5. It can be concluded that effects of pellet weight on energy consumption were more significant at the higher level of ultrasonic power.

For interaction effects of sieve size and pellet weight, energy consumption increased from 3.10 to $3.64 \mathrm{Wh}$ (increased by $0.54 \mathrm{Wh}$ ) at a higher sieve size level $(8 \mathrm{~mm}$ ); while it increased from 3.07 to $3.23 \mathrm{Wh}$ (increased by $0.16 \mathrm{Wh})$ at a lower sieve size level (2 mm) when pellet weight increased from 1 to $3 \mathrm{~g}$, as shown in Figure 6 . This indicated that the effects of pellet weight on energy consumption were more significant at the higher level of sieve size.

\subsection{Optimization of process parameters}


Process optimization to minimize the energy consumption of UV-A pelleting was conducted on the Minitab software (Minitab, Inc., State College, PA, USA) using the "response optimizer" function. Within the tested experimental ranges, the optimum values of the process parameters are list in Table 2 and the corresponding minimum energy consumption within the tested experimental ranges is $2.62 \mathrm{Wh}$.

To compare the results achieved from the model with experiments, additional confirmation experiments were conducted under process parameters settings: ultrasonic power at 20\%, sieve size at $4 \mathrm{~mm}$ (4.7 $\mathrm{mm}$ sieve size was not available), and pellet weight at $1 \mathrm{~g}$. As shown in Table 3, the energy consumption obtained from the confirmation experiments was very close to that estimated by the RSM model, implying that the RSM approach was appropriate for optimizing the process parameters of the UV-A pelleting process in order to minimize the energy consumption.

\section{CONCLUSIONS}

This paper employed response surface methodology to develop a predictive model for the energy consumption in UV-A pelleting of wheat straw. The model can predict effects of pelleting pressure, ultrasonic power, sieve size, and pellet weight on the energy consumption. It was found that three parameters (ultrasonic power, sieve size, and pellet weight) significantly affected energy consumption in UV-A pelleting. Within the tested experimental ranges, energy consumption increased when ultrasonic power, sieve size, and pellet weight increased. Pelleting pressure had no significant effect on the energy consumption in UV-A pelleting. In addition, two of the predicted two-factor interaction effects (ultrasonic power $\times$ pellet weight and sieve size $\times$ pellet weight) were significant. Effects of pellet weight on energy consumption were more significant at the higher level of ultrasonic power and at the higher level of sieve size.

Minimum energy consumption (2.54 Wh) within the tested experimental ranges was obtained with ultrasonic power at $20 \%$, sieve size at $4 \mathrm{~mm}$, and pellet weight at $1 \mathrm{~g}$. The result of the confirmation experiments was found to be in good agreement with the values predicted by the RSM model, which demonstrated that to obtain a maximum amount of information in a short period of time, with the least number of experiments, RSM can be successfully applied to modeling and optimizing the UV-A pelleting process. Results from this work would also provide useful information to open up a life-cycle assessment to investigate the viability of employing UV-A pelleting of biomass as a pre-processing step in cellulosic biofuel manufacturing. 
Pellet durability and sugar yield are other important outputs in UV-A pelleting. Investigations of pellet durability and sugar yield will be part of the future work. In addition, the temperature of biomass increased significantly in UV-A pelleting [22]. A systematic study on effects of process parameters on temperature of biomass in UV-A pelleting is underway.

\section{ACKNOWLEDGEMENTS}

The authors acknowledge the U.S. National Science Foundation for providing funding (Award Number 0970112) for this research and China Scholarship Council for providing scholarship for the first two authors. The authors also acknowledge Mr. Clyde Treadwell at Sonic Mill Inc. for providing the equipment. Special thanks go to Dr. Weilong Cong at Kansas State University for many helpful discussion and suggestions.

\section{REFERENCES}

[1] U.S. Energy Information Administration, Monthly energy review, $<$ http://www.eia.gov/totalenergy/data/monthly/pdf/mer.pdf > (last accessed on June 20, 2013).

[2] U.S. Energy Information Administration, Transportation sector energy consumption estimates: 1949-2011, $<$ http://www.eia.gov/totalenergy/data/annual/showtext.cfm?t=ptb0201e > (last accessed on June 20, 2013).

[3] U.S. Energy Information Administration, U.S. energy consumption by sector of 1949-2010, $<$ http://www.eia.gov/totalenergy/data/annual/txt/ptb0201a.html> (last accessed on June 20, 2013).

[4] U.S. Energy Information Administration, Energy in brief: how dependent are we on foreign oil? $<$ http://www.eia.gov/energy_in_brief/article/foreign_oil_dependence.cfm> (last accessed on June 20, 2013).

[5] U.S. Energy Information Administration, Short-term energy outlook (STRO), $<$ http://www.eia.gov/forecasts/steo/pdf/steo_full.pdf> (last accessed on June 20, 2013).

[6] J. Conti, N. Chase, J. Maples, US Greenhouse gas emissions in the transportation sector, in: D. Sperling, J.S. Cannon (Eds.), Climate and Transportation Solutions: Findings from the 2009 Conference on Transportation and Energy Policy', Institute of Transportation Studies, University of California, Davis, 2010, pp. 24-32.

[7] U.S. Environmental Protection Agency, Inventory of U.S. greenhouse gas emissions and sinks: 1990-2009, <http://www.epa.gov/climatechange/Downloads/ghgemissions/US-GHG-Inventory-2013-Main-Text.pdf> (last accessed on June 20, 2013).

[8] National Academy of Sciences, National Academy of Engineering, National Research Council, Liquid Transportation Fuels from Coal and Biomass: Technological Status, Costs, and Environmental Impacts, The National Academies Press, Washington, DC, 2009.

[9] M. Wang, M. Wu, H. Huo, J.H., Liu, Life-cycle energy use and greenhouse gas emission implications of Brazilian sugarcane ethanol simulated with the GREET model, Int. Sugar J. 110 (2008) 527-545.

[10] Renewable Fuels Association, Ethanol facts: environment, <http://www.ethanolrfa.org/pages/ethanol-factsenvironment> (last accessed on June 20, 2013).

[11] K.A. Gray, L. Zhao, M. Emptage, Bioethanol, Curr. Opin. Chem. Biol. 10 (2006) 141-146.

[12] L.R. Brown, Why ethanol production will drive world food prices even higher in 2008, <http://www.earthpolicy.org/plan_b_updates/2008/update69> (last accessed on June 20, 2013). 
[13] R.H. Leaver, The Pelleting Process, Sprout-Waldron, Muncy, PA, 1984.

[14] S. Mani, S. Sokhansanj, X. Bi, A. Turhollow, Economics of producing fuel pellets from biomass, Appl. Eng. Agric. 22 (2006) 421-426.

[15] S. Sokhansanj, S. Mani, X. Bi, P. Zaini, L. Tabil, Binderless pelletization of biomass, in: Proceedings of the ASAE Annual International Meeting, Tampa, FL, July 17-20, 2005.

[16] Z.J. Pei, D. Wang, R. Clark, Ultrasonic vibration-assisted pelleting of cellulosic biomass: a preliminary experiment, in: Proceedings of the ASME 2009 International Manufacturing Science \& Engineering Conference, West Lafayette, IN, October 4-7, 2009.

[17] X.X. Song, M. Zhang, Z.J. Pei, Effects of ultrasonic vibration-assisted pelleting of cellulosic biomass on sugar yield for biofuel manufacturing, Biomass Conversion and Biorefinery. May (2013) 1-8, 10.1007/s13399-013-0078-2.

[18] X.X. Song, M. Zhang, Z.J. Pei, T. Deines, Ultrasonic vibration-assisted pelleting of cellulosic biomass: effects of moisture content, in: Proceedings of the IIE Annual Conference and Expo, Cancun, Mexico, June 5- 9, 2010.

[19] X.X. Song, M. Zhang, T.W. Deines, P.F. Zhang, Z.J. Pei, Energy consumption study in ultrasonic vibrationassisted pelleting of wheat straw for cellulosic biofuel manufacturing, International Journal of Manufacturing Research. 8 (2012) 135-149.

[20] M. Zhang, X.X. Song, T.W. Deines, P.F. Zhang, Q. Zhang, W.L. Cong, et al., Vibration-assisted pelleting of switchgrass: effects of binder material, in: Proceedings of the IIE Annual Conference and Expo, Cancun, Mexico, June 5- 9, 2010.

[21] M. Zhang, X.X. Song, Z.J. Pei, T.W. Deines, C. Treadwell, Ultrasonic vibration-assisted pelleting of wheat straw: an experimental investigation, International Journal of Manufacturing Research. 7 (2012) 59-71.

[22] Q. Feng, W.L. Cong, M. Zhang, Z.J. Pei, C. Ren, An experimental study on temperature in ultrasonic vibration-assisted pelleting of cellulosic biomass, in: Proceedings of the ASME 2010 International Manufacturing Science and Engineering Conference, Erie, PA, October 12-15, 2010.

[23] Q. Feng, W.L. Cong, M. Zhang, Z.J. Pei, An experimental study on charring of cellulosic biomass in ultrasonic vibration-assisted pelleting, International Journal of Manufacturing Research. 6 (2011) 77-86.

[24] Y.J. Tang, C.M. Chen, G. Wang, Temperature on-line measured in ultrasonic vibration-assisted pelleting cellulosic biomass, Applied Mechanics and Materials. 151 (2012) 245-249.

[25] P.F. Zhang, T.W. Deines, D. Nottingham, Z.J. Pei, D. Wang, X. Wu, Ultrasonic vibration-assisted pelleting of biomass: a designed experimental investigation on pellet quality and sugar yield, in: Proceedings of the ASME 2010 International Manufacturing Science and Engineering Conference , Erie, PA, October 12-15, 2010.

[26] B. Salamatinia, H. Mootabadi, S. Bhatia, A.Z. Abdullah, Optimization of ultrasonic-assisted heterogeneous biodiesel production from palm oil: a response surface methodology approach, Fuel Process. Technol. 91 (2010) 441-448.

[27] F. Xu, K. Theerarattananoon, X. Wu, L. Pena, Y.C. Shi, S. Staggenborg, et al., Process optimization for ethanol production from photoperiod-sensitive sorghum: focus on cellulose conversion, Ind. Crop. Prod. 34 (2011) 1212-1218.

[28] A. Sluiter, B. Hames, D. Hyman, C. Payne, R. Ruiz, C. Scarlata, et al., Determination of total solids in biomass and total dissolved solids in liquid process samples, NREL/TP-510-42621. $<$ http://www.nrel.gov/biomass/pdfs/42621.pdf> (last accessed on June 20, 2013).

[29] S. Herman, Electrical Studies for Trades, fourth ed., Delmar, Cengage Learning, Inc., Clifton Park, NY, 2009.

[30] Q. Zhang, P.F. Zhang, Z.J. Pei, J. Wilson, L. McKinney, G. Pritchett, Ultrasonic-vibration assisted pelleting for cellulosic ethanol manufacturing: an experimental investigation of power consumption, in: Proceedings of the ASME 2011 International Mechanical Engineering Congress and Exposition, Denver, CO, November 1117, 2011. 
[31] Q. Zhang, P.F. Zhang, Z.J. Pei, M. Zhang, X.X. Song, T. Deines, et al., Ultrasonic-vibration assisted pelleting for cellulosic ethanol manufacturing: investigation of power consumption with design of experiment, in: Proceedings of the ASME 2012 International Manufacturing Science and Engineering Conference, Notre Dame, IN, June 4-8, 2012.

[32] S.L.C. Ferreira, R.E. Bruns, H.S. Ferreira, G.D. Matos, J.M. David, G.C. Brandão, et al., Box-Behnken design: an alternative for the optimization of analytical methods, Anal. Chim. Acta. 597 (2007) 179-186.

[33] N.K. Rastogi, K.R. Rashmi, Optimisation of enzymatic liquefaction of mango pulp by response surface methodology, Eur. Food Res. Technol. 209 (1999) 57-62.

[34] W.L. Cong, Z.J. Pei, T.W. Deines, A. Srivastava, L. Riley, C. Treadwell, Rotary ultrasonic machining of CFRP composites: a study on power consumption, Ultrasonics. 52 (2012) 1030-1037.

[35] X.X. Song, M. Zhang, Z.J. Pei, T. Deines, Ultrasonic-vibration-assisted pelleting of cellulosic biomass: effects of moisture content, in: Proceedings of the ASME 2010 International Manufacturing Science and Engineering Conference, Erie, PA, October 12-15, 2010.

[36] Q. Zhang, P.F. Zhang, T. Deines, Z.J. Pei, D. Wang, X. Wu, et al., Ultrasonic vibration-assisted pelleting of sorghum stalks: effects of pressure and ultrasonic power, in: Proceedings of the ASME 2010 International Manufacturing Science and Engineering Conference, Erie, PA, October 12-15, 2010.

[37] B. Svihus, K.H. Kløvstad, V. Perez, O. Zimonja, S. Sahlström, R.B. Schüller, et al., Physical and nutritional effects of pelleting of broiler chicken diets made from wheat ground to different coarsenesses by the use of roller mill and hammer mill, Anim. Feed Sci. Tech. 117 (2004) 281-293.

[38] Q. Zhang, P.F. Zhang, T.W. Deines, M. Zhang, X.X. Song, Z.J. Pei, Ultrasonic vibration-assisted pelleting of wheat straw: effects of particle size, in: Proceedings of the 20th International Conference on Flexible Automation and Intelligent Manufacturing, Oakland, CA, July 12-14, 2010.

[39] K. Theerarattananoon, F. Xu, J. Wilson, S. Staggenborg, L. McKinney, P. Vadlani, et al., Effects of the pelleting conditions on chemical composition and sugar yield of corn stover, big bluestem, wheat straw, and sorghum stalk pellets, Bioprocess Biosyst. Eng. 35 (2012) 615-623.

[40] L. Tabil, S. Sokhansanj, Process conditions affecting the physical quality of alfalfa pellets, Appl. Eng. Agric. 12 (1996) 345-350.

[41] Y.J. Tang, P.F. Zhang, D.F. Liu, Z.J. Pei, Effects of pellet weight in ultrasonic vibration-assisted pelleting for cellulosic biofuel manufacturing, International Journal of Manufacturing Research. 7 (2012) 397-408. 


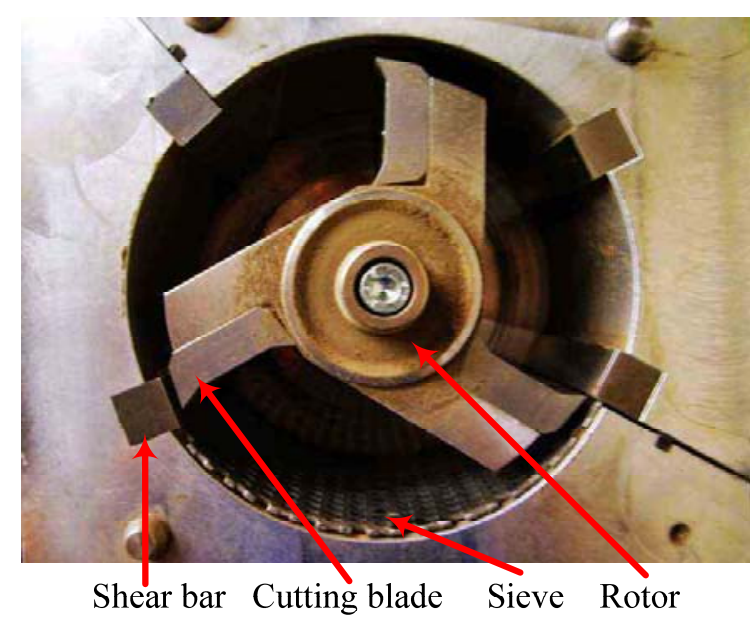

Figure 1 Milling chamber of knife mill 


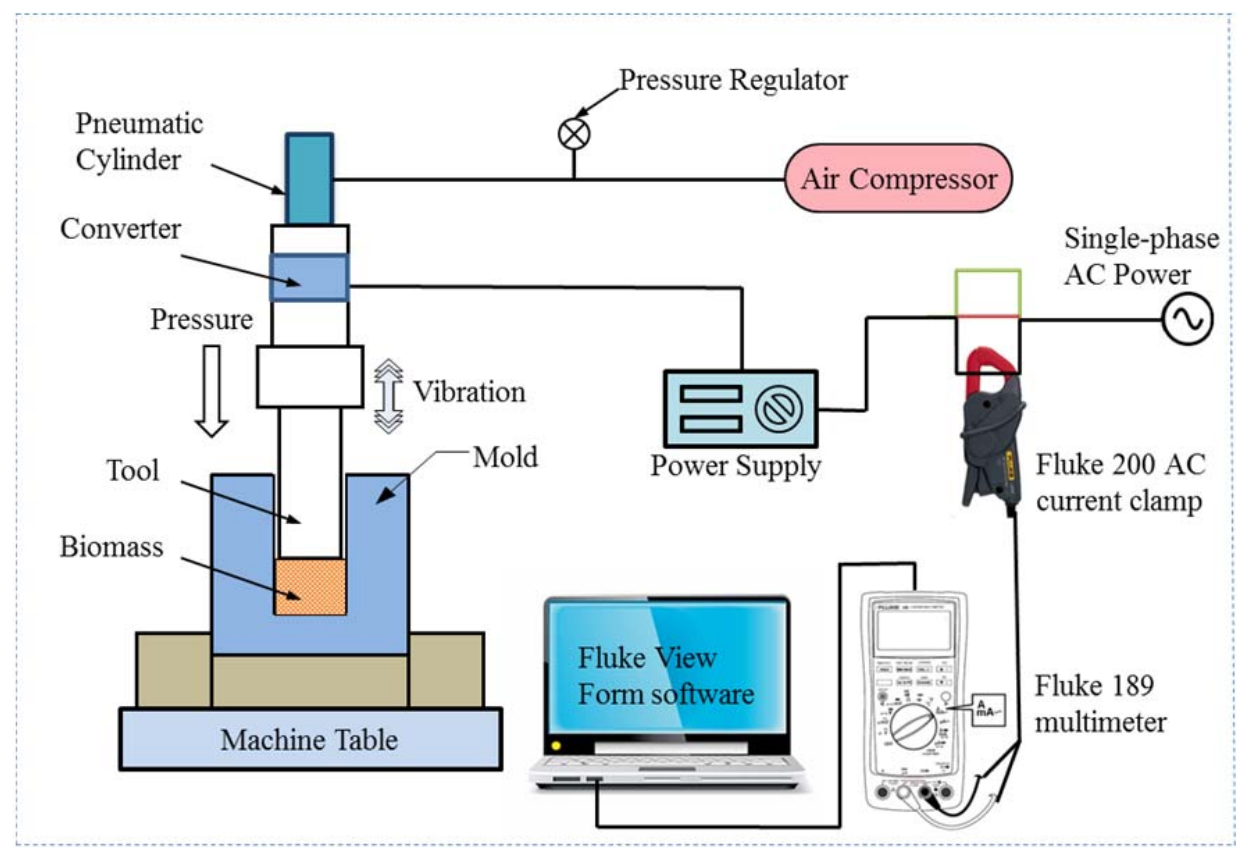

Figure 2 Illustration of the experimental set-up for UV-A pelleting 


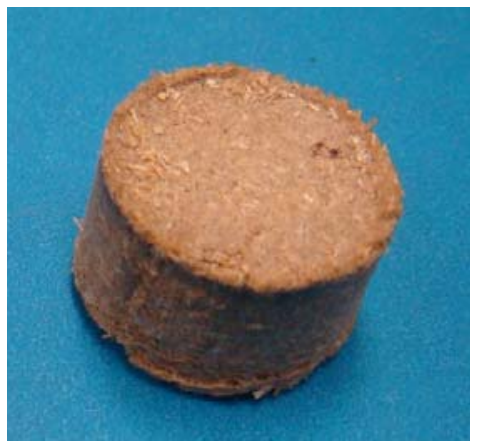

Figure 3 Picture of a pellet produced by UV-A pelleting 


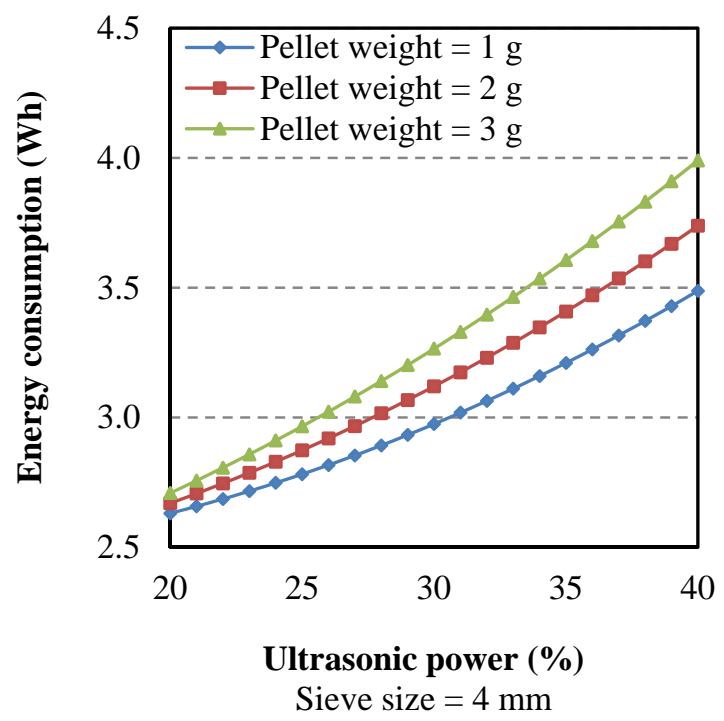

Figure 4A Effects of ultrasonic power on the energy consumption in UV-A pelleting 


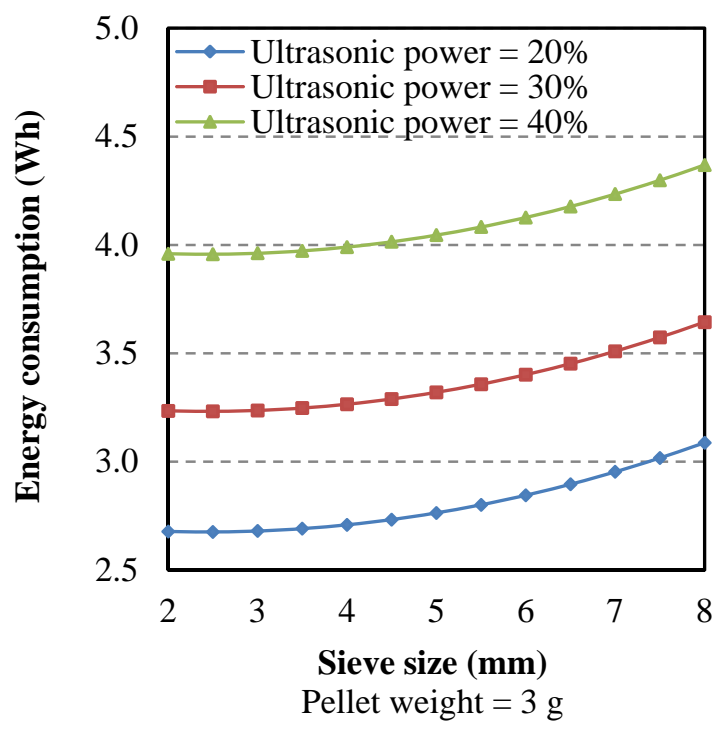

Figure 4B Effects of sieve size on the energy consumption in UV-A pelleting 


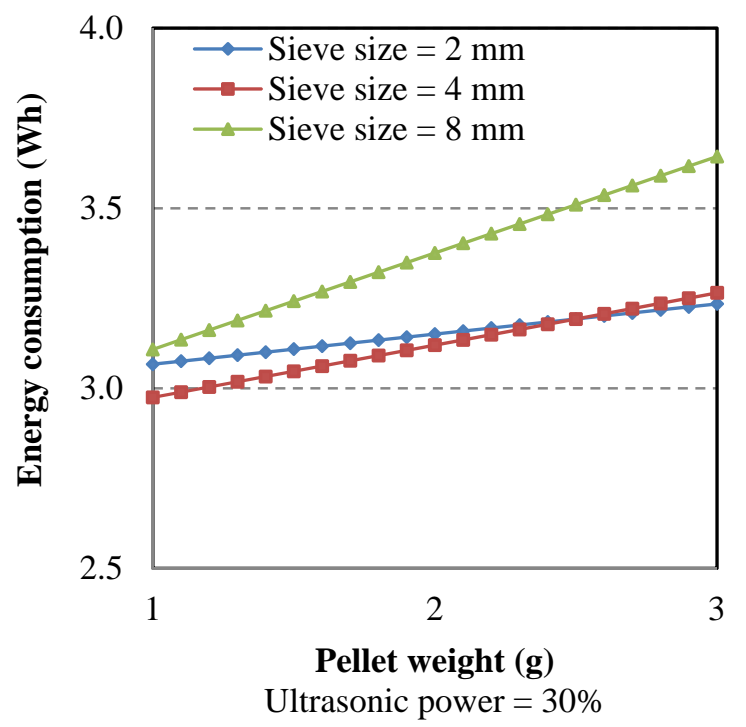

Figure 4C Effects of pellet weight on the energy consumption in UV-A pelleting 


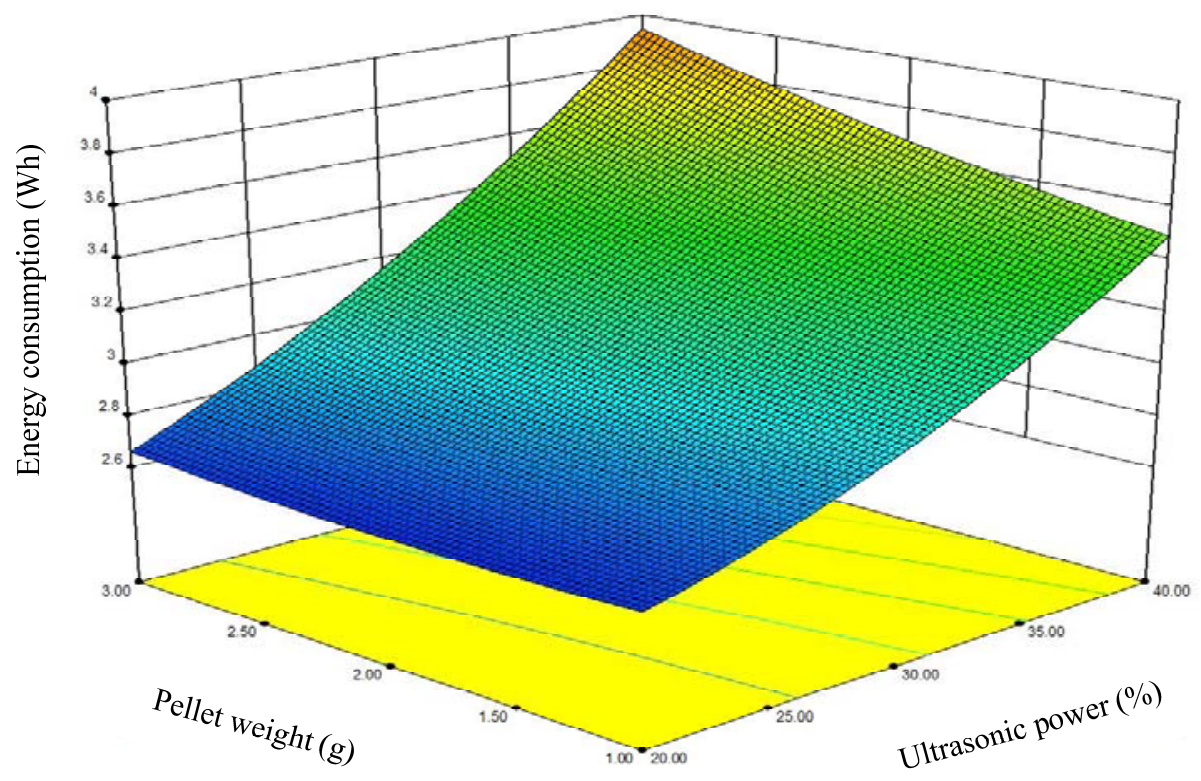

Figure 5 3-D response surface of the energy consumption in relation to ultrasonic power and pellet weight (sieve size $=4 \mathrm{~mm}$, pelleting pressure $=40 \mathrm{psi})$ 


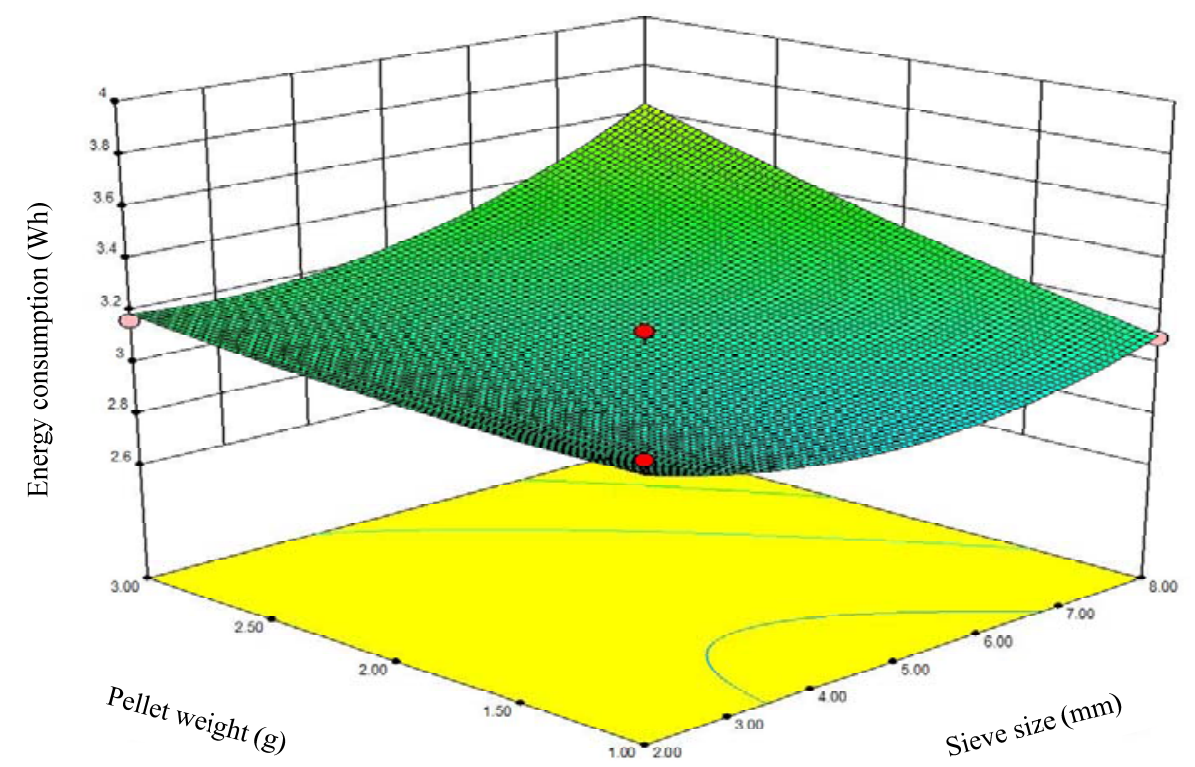

Figure 6 3-D response surface of the energy consumption in relation to sieve size and pellet weight (ultrasonic power $=30 \%$, pelleting pressure $=\mathbf{4 0} \mathrm{psi}$ ) 
Table 1 Experimental design and results

\begin{tabular}{|c|c|c|c|c|c|}
\hline Run order & $\begin{array}{c}\text { Pelleting } \\
\text { pressure (psi) }\end{array}$ & $\begin{array}{l}\text { Ultrasonic } \\
\text { power (\%) }\end{array}$ & $\begin{array}{l}\text { Sieve size } \\
\quad(\mathrm{mm})\end{array}$ & $\begin{array}{c}\text { Pellet } \\
\text { weight (g) }\end{array}$ & $\begin{array}{l}\text { Energy } \\
\text { consumption } \\
\text { (Wh) }\end{array}$ \\
\hline 1 & 40 & 40 & 4 & 1 & 3.47 \\
\hline 2 & 40 & 30 & 4 & 2 & 3.07 \\
\hline 3 & 40 & 20 & 4 & 1 & 2.54 \\
\hline 4 & 40 & 40 & 8 & 2 & 3.98 \\
\hline 5 & 50 & 30 & 8 & 2 & 3.58 \\
\hline 6 & 40 & 30 & 4 & 2 & 3.04 \\
\hline 7 & 30 & 30 & 8 & 2 & 3.30 \\
\hline 8 & 50 & 40 & 4 & 2 & 3.73 \\
\hline 9 & 40 & 30 & 2 & 3 & 3.17 \\
\hline 10 & 50 & 30 & 4 & 1 & 2.95 \\
\hline 11 & 40 & 40 & 4 & 3 & 4.14 \\
\hline 12 & 30 & 20 & 4 & 2 & 2.69 \\
\hline 13 & 40 & 30 & 8 & 3 & 3.56 \\
\hline 14 & 40 & 30 & 2 & 1 & 3.16 \\
\hline 15 & 30 & 30 & 4 & 3 & 3.29 \\
\hline 16 & 50 & 30 & 2 & 2 & 3.18 \\
\hline 17 & 30 & 40 & 4 & 2 & 3.66 \\
\hline 18 & 40 & 30 & 8 & 1 & 3.10 \\
\hline 19 & 40 & 20 & 4 & 3 & 2.80 \\
\hline 20 & 40 & 20 & 2 & 2 & 2.66 \\
\hline 21 & 40 & 40 & 2 & 2 & 3.74 \\
\hline 22 & 40 & 30 & 4 & 2 & 3.13 \\
\hline 23 & 30 & 30 & 2 & 2 & 3.16 \\
\hline 24 & 30 & 30 & 4 & 1 & 3.07 \\
\hline 25 & 50 & 30 & 4 & 3 & 3.21 \\
\hline 26 & 50 & 20 & 4 & 2 & 2.70 \\
\hline 27 & 40 & 20 & 8 & 2 & 2.92 \\
\hline
\end{tabular}


Table 2 Optimal values of parameters obtained from response surface model to minimize the energy

\begin{tabular}{cc}
\multicolumn{2}{c}{ consumption in UV-A pelleting } \\
\hline Parameters & Optimal values \\
\hline Ultrasonic power (\%) & 20 \\
Sieve size (mm) & 4.7 \\
Pellet weight (g) & 1 \\
\hline
\end{tabular}


Table 3 Results of confirmation experiments

\begin{tabular}{|c|c|c|c|c|}
\hline & \multicolumn{3}{|c|}{ UV-A pelleting parameters } & \multirow{2}{*}{$\begin{array}{c}\text { Response } \\
\text { Energy } \\
\text { consumption } \\
(\mathrm{Wh})\end{array}$} \\
\hline & Ultrasonic power (\%) & Sieve size $(\mathrm{mm})$ & $\begin{array}{l}\text { Pellet } \\
\text { weight (g) }\end{array}$ & \\
\hline Experimental value & 20 & 4 & 1 & $2.54(0.04)^{*}$ \\
\hline Predicted value & 20 & 4.7 & 1 & 2.62 \\
\hline Error (\%) & 0 & 17.5 & 0 & $3.20(1.39)^{*}$ \\
\hline
\end{tabular}

${ }^{*}$ means and stand deviations were calculated based on five observations 